\title{
Refurbishment of a house in a historical building: energy saving, electrification and flexibility
}

\author{
Giada Romano , Elisa Pennacchia ${ }^{\square}$, and Sofia Agostinelli ${ }^{\square}$ \\ ${ }^{\square}$ Department of Planning, Design and Technology of Architecture, Sapienza University of Rome, Via Flaminia 72, \\ Q0196 Rome, Italy \\ ${ }^{2}$ Interdepartmental Centre for Landscape, Building, Conservation, Environment (CITERA), Sapienza University of \\ Rome, Via A. Gramsci, 53-00197 Rome, Italy;
}

\begin{abstract}
Buildings with architectural constraints and recognized historical values require a careful design process, aiming to combine the needs of conservation and the adaptation of the buildings to the modern use and its accessibility. The feasible interventions consist in improving the energy performance of the building envelope, in inserting efficient technological systems and using renewable energy sources where possible. The compatibility between the architectural constraints of the building and its more sustainable future use represents a crucial challenge. This work presents the interventions designed and realized on a small villa located in the Prati district, in Rome. Starting from the requests of the client, the primary objective was to create a comfortable house both in the winter and in the summer season, with widespread use of automation systems for managing the utilities. In line with the current energy scenario, the interventions were oriented to energy efficiency, the reduction of polluting emissions, the electrification of utilities and the use of renewable energy sources. The proposed solutions showed high gains in terms of energy saving even if the changes to the building envelope were limited by the desire to preserve the values of the cultural heritage. Therefore, a virtuous refurbishment can effectively respond to current energy efficiency goals.
\end{abstract}

\section{Introduction}

The European Community has clearly outlined its objectives in terms of environmental sustainability, indicating ambitious targets for reducing energy consumption, reducing emissions and increasing the use of renewable energy sources [1]. Technological planning has a key role, seen the light of three major challenges raised by the environmental and energy-related issues of our time, meaning climate change, limited sources and excessive energy consumption [2].

A large part of the reduction in energy consumption will occur in buildings, both in the residential and in the services sector, which today are responsible for a very important share $(>40 \%)$ of total energy consumption [3]. This will require higher renovation rates and energy carrier changes, with a large majority of dwellings using renewable heating sources (electricity, district heating, renewable gas or solar thermal) [4], the diffusion of more efficient products and appliances, smart management systems of buildings and energy uses in general.

As for renewable energies, the European Commission has established that the contribution of renewable energies in 2030 will cover $32 \%$ of final energy consumption; there will be a strong increase in the production of electricity from RES, with new plants that will have to be installed primarily on already exploited soil [5,6], at the same time, large-scale electrification of the energy system will be achieved. The introduction of alternative energy sources in the supply mix will require proper management of flexible loads (DSM - Demand Side Management) to improve efficiency and stabilize the network, even facilitated by introduction of storage, when possible [7].

In this context, for a correct energy requalification of the existing building patrimony, guidelines and good practices will have to be developed to adapt the patrimony to modern needs of use and comfort and to adapt buildings to climate change [8]; wherever possible, efforts should be made to achieve the nZEB standard [9-11], with an integrated restructuring, which takes into account Indoor Environmental Quality 
(IEQ) [12], which includes the exploitation of renewable energy resources, with the introduction of automation systems for the management of flexible loads [13,14]; particular attention must be paid to the buildings subject to protection, for which an improvement in performance will be sought, in compliance with historical and architectural values [15-17], a massive intervention in the energy upgrade of the cultural heritage is necessary not to vain the efforts made in recent decades to achieve the objectives of the EU's "Climate Change Package" [18]. In an urban environment, the use of those energy vectors that allow limiting local polluting emissions should be preferred [19-21].

This work describes a redevelopment intervention of a house inserted in a building subject to protection. Following a change of ownership, the new owners expressed the desire for an overall renovation of the house, with modern plant equipment that made it comfortable both in the winter season and in the summer season, including automation systems for automatic management of the utilities. The design team interpreted the client's requests on the basis of the energy scenarios described above; for this reason, the design choices have been oriented not only to the search for environmental comfort but also to the search for energy efficiency, the reduction of polluting emissions, the electrification of utilities and the use of renewable energy resources.

\section{Villino Cagiati in Rome}

The Prati district in Rome, in the context of the urbanization of the early twentieth century, was chosen among the new expanding areas envisaged by the General Town Plan, for the construction of charming art nouveau villas for the new bourgeois Roman class, which developed until 1920; the small villa Cagiati, the small villa Vitale, the small villa Brunialti and many others, among them. The small villa Cagiati (Fig.1) is located at the end of Via Virginio Orsini, on the right, before Piazza della Libertà, at the corner with Via dei Gracchi.
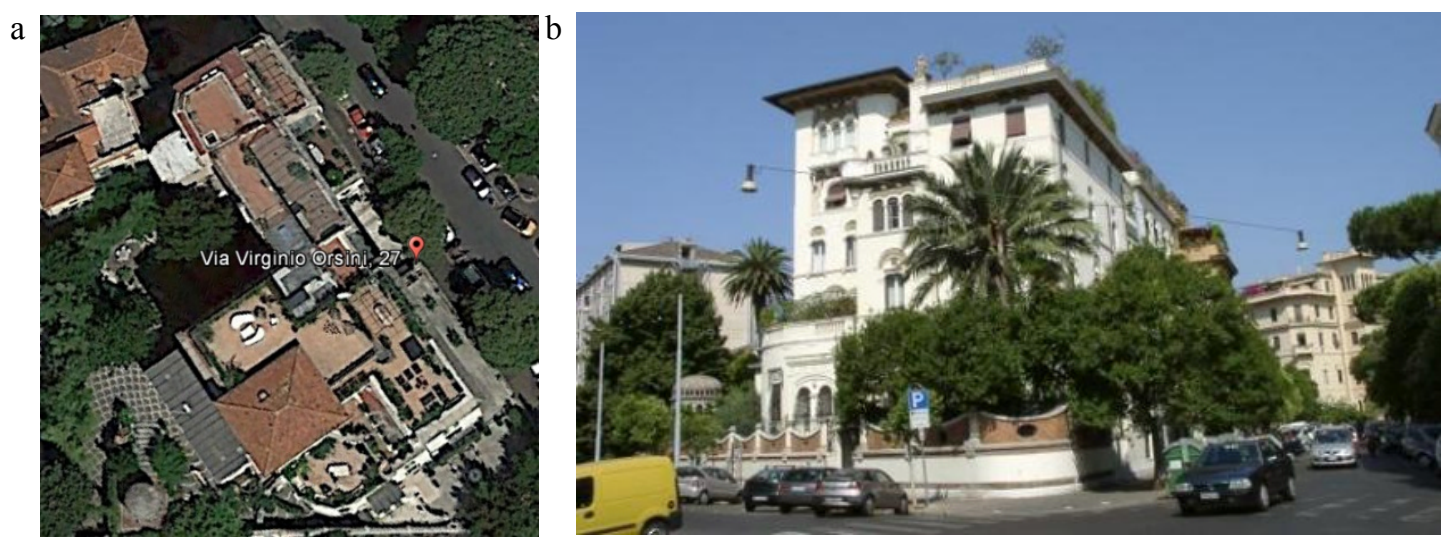

Fig. 1. Villino Cagiati (a) Aerial view; (b) View from Piazza della Libertà.

The house was designed by the architect Garibaldi Burba and built for Giulio Cagiati. It undoubtedly represents one of the most unique realizations of the theme of the villa of the early twentieth century in Rome. Built in 1902, after a careful restoration work that cleaned its façade and above all the various decorative elements (metal, stone, ceramic), today it appears as one of the best preserved Liberty works in the city. In addition to the architect Garibaldi Burba, important figures of the Roman art world actively participated in the project: Galileo Chini oversaw the external decoration in polychrome majolica with flowers and fruit motifs; Silvio Galimberti designed the fresco decorations; Alessandro Mazzucottelli developed the elegant solutions in wrought iron with a triumph of vegetable elements with vine shoots. The product of this work is one of the most identifying houses of the Liberty in Rome.

Even if subsequently raised with alteration of the original volume, the main lines are still clearly legible. The construction is characterized by a marked search for the corner solution as it rises on the corner of two streets. The main entrance is sideways through two arches. A large upper terrace divides the street level from the ground floor of the building, which is raised. A square tower almost connects the two 
volumes. The terrace (above the street level) contains the deposits, the garages and above the roof garden, which is enriched by a beautiful circular gazebo with a dome on arches, all strongly influenced by Arabic style lines.

The building is decorated on the façade with frescoes with Latin mottos and friezes of the attic with wide motifs of interwoven sunflowers (Fig.2). The decorations arouse particular interest: the frescoes by Galimberti outside the villa, and the friezes in majolica tiles, the reliefs with the motifs of heads of Gorgon on the perimeter fence and, in particular, the valuable wrought iron with leaves of lives from the famous Alessandro Mazzucotelli workshop. The attic with a painting showing sunflowers is wonderful, above and below the windows there are other floral paintings, the light holders at the entrance are particular.
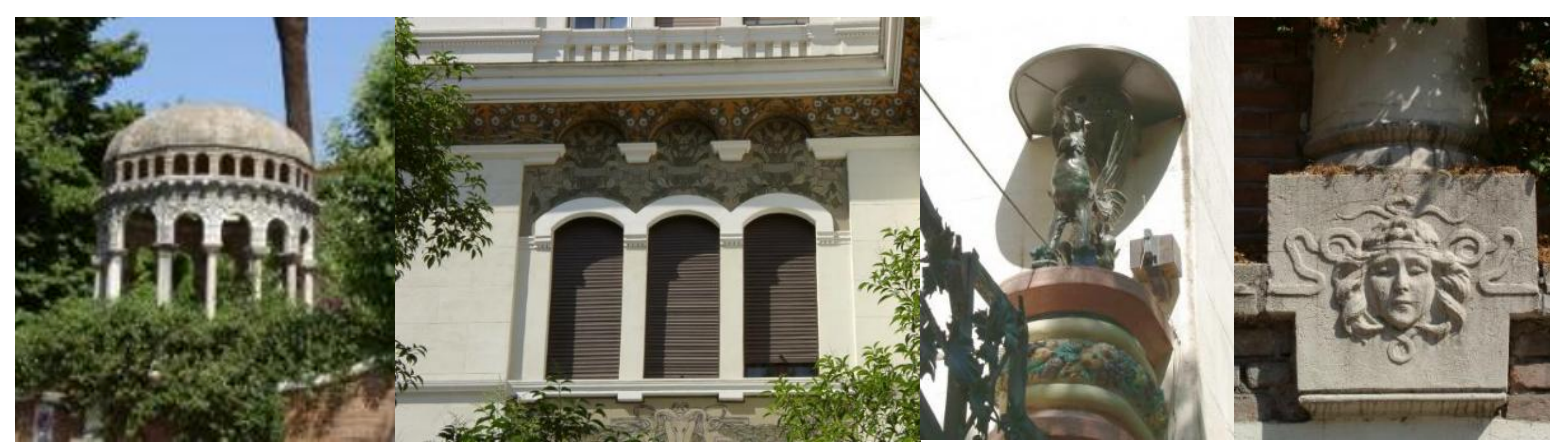

Fig. 2. Villino Cagiati - Decorative elements.

\section{Materials and Methods}

In order to evaluate the effectiveness of the proposed interventions, a simulation of the energy performance of the building has been carried out, using a calculation tool developed within the research group and allowing a dynamic simulation of the building, with modeling of a single thermal zone. Interviews with the design team made it possible to gather useful information for the simulation, referring to the building envelope (building location, surfaces, orientation, U-value building envelope, air exchange rate, shadings), to the systems (heating system, cooling system, domestic hot water plant) and appliances and devices (Kitchen, Refrigeration, Washing, Cleaning and ironing, Lighting, Audio/Video, Personal Care, Other equipment); the apartment is not inhabited yet, so the information regarding the occupation and use modalities of the building have been estimated on the basis of average values, as resulting from studies done previously [22] carefully accounting for the possible performance gap [23].

For the comparison between the ante-operam and post-operam situation, six indicators have been used: (i) winter thermal load; (ii) summer thermal load; (iii) the energy consumption; (iv) renewable energy use;

(v) local carbon emissions and (vi) flexible loads amount.

These six indicators allow us to numerically evaluate different aspects of the intervention [24].

Through the winter and summer thermal load the effectiveness of the interventions on the building envelope can be evaluated; the lower the values of the thermal loads and the greater the effectiveness of the interventions on the building envelope; moreover, low values of the thermal loads allow to minimize the space occupied by the heating and cooling systems (generation equipment, piping and distribution ducts, emission terminals); this aspect is extremely important in buildings with historical or architectural constraints.

Energy consumption is the most commonly used indicator for assessing the energy performance of a building and is often assessed at the same time as renewable energy uses; this is the approach currently used by Italian building energy certification system.

As regard the calculation methods, there is an evident correlation between global emissions and the energy consumption. For this reason, it has been chosen to consider local emissions rather than the global ones.

The evaluation of flexible electrical loads is a novelty of this study, as it is not generally used for residential users. The main flexible loads in dwellings are "storable loads", i.e. heating, cooling, Domestic 
Hot Water when equipped with battery or water tank and "shiftable loads", i.e. laundry, dishwasher, tumble dryer, vacuum cleaner, stove.

\section{Results and Discussion}

\subsection{Description of the ante operam situation}

The redevelopment project refers to a house located on the fourth (attic) and fifth (super attic) floor of the building. It has been obtained by combining the house present on the fourth floor and the wash houses originally present on the fifth floor. The useful surface on the fourth floor is approximately $205 \mathrm{~m}^{2}$, with an average height of $3.3 \mathrm{~m}$; the usable area on the fifth floor is approximately $90 \mathrm{~m}^{2}$, with an average height of $2.3 \mathrm{~m}$.

Before the refurbishment design, a study on the thermo-physical characteristics and the installed HVAC systems was carried out by means of on-site survey. Furthermore, related bibliography as well as original architectural drawings were analyzed along with infrared camera use and surveying the inhabitants.

The opaque portion of the building envelope was free of insulating material, with the only exception of the terrace covering of a part of the fourth floor that was renovated in the 1990s. The perimeter walls of the fourth floor were in tuff with thicknesses varying between 50 and $60 \mathrm{~cm}$; the perimeter walls of the fifth floor (former wash houses) were in solid bricks with very small thickness $(10-20 \mathrm{~cm})$.

The windows on the main façade were still the original ones, made of wood with single glass; on the rear elevation there were instead aluminium window frames with double glazing.

Table 1 reports the U-value of all the building components.

Table 1. U-value of building envelope components.

\begin{tabular}{lcc}
\hline Description & $\begin{array}{c}\text { Thickness } \\
{[\mathrm{m}]}\end{array}$ & $\begin{array}{c}\mathrm{U} \\
{\left[\mathrm{W} / \mathrm{m}^{2} \mathrm{~K}\right]}\end{array}$ \\
\hline Load-bearing masonry in tuff & $0.40 \div 0.68$ & $1.49 \div 0.98$ \\
Solid brick masonry & $0.10 \div 0.30$ & $2.57 \div 1.83$ \\
Original wooden windows with single glass & - & 5.53 \\
Aluminum windows with double glazing & - & 3.26 \\
Roof slab, with insulation & 0.35 & 0.79 \\
Floor between inhabited areas, not isolated & 0.32 & 1.44 \\
\hline
\end{tabular}

The original HVAC system was composed by centralized heating system and autonomous domestic hot water production. During previous renovations, in all the houses were installed independent gas boilers with the elimination of the central heating system. The terminals of the heating system were radiators; the system was adjusted using a single programmable thermostat. In the original configuration of the building, there were no cooling systems; only later split-unit systems (air-to-air heat pump) were added to some rooms. In the considered house there were split units only for the bedrooms.

The lighting system was equipped with incandescent or compact fluorescent lamps.

\subsection{Description of the post operam situation}

As said, the primary objective of the refurbishment was to create a comfortable dwelling both in the winter and in the summer season. For this reason, particular care has been taken to improve the passive performance of the building envelope.

Accounting for the architectural constraints, two aspects have been investigated for energy refurbishment interventions:

- a first solution is to improve building envelope thermodynamic performance in order to reduce heating and cooling demand as well as increasing the effects of passive solutions;

- a second aspect is to design the improvement strategy on the HVAC system side in order to increase the production efficiency, integrate a higher share of renewables to meet building energy demand. 
As regards the opaque portion of the building envelope, insulating material have been added everywhere, using panels in rigid expanded polyiso foam (PIR) with waterproof coating on both sides; panels of variable thickness between 6 and $10 \mathrm{~cm}$ have been used depending on the possibilities, not to excessively reduce the size of the rooms, especially for the small size ones.

With regard to the windows we have proceeded with two different methods; for the original wooden window frames, it has been decided to keep the frame, replacing the glass and inserting a 4-9-4 type glass compatible with the existing dimensions; the non-original aluminum frames have been replaced with wooden ones with 4-20-4 type glass. It has been decided to use solar control glass with a low solar gain factor $(g=0.2)$ everywhere, due to problems of possible overheating during the summer.

Table 2 reports the $U$-value of all the building components in the refurbished configurations.

Table 2. U-value of each building envelope components in the refurbished configurations.

\begin{tabular}{lcc}
\hline Description & $\begin{array}{c}\text { Thickness } \\
{[\mathrm{m}]}\end{array}$ & $\begin{array}{c}\mathrm{U} \\
{\left[\mathrm{W} / \mathrm{m}^{2} \mathrm{~K}\right]}\end{array}$ \\
\hline Load-bearing masonry in tuff, with insulation & $0.46 \div 0.74$ & $0.48 \div 0.41$ \\
Solid brick masonry, with insulation & $0.18 \div 0.38$ & $0.45 \div 0.42$ \\
Original wooden windows with single glass & - & 2.1 \\
Aluminum windows with double glazing & - & 1.88 \\
Roof slab, with insulation & 0.42 & 0.34 \\
Floor between inhabited areas, not isolated & 0.32 & 1.44 \\
\hline
\end{tabular}

For the systems, the house has been equipped in all the rooms of heating and cooling system; with air/water electric heat pump ( $\mathrm{COP}=5.00$; $\mathrm{EER}=3.3)$; the terminals in each room are radiant floor panels and ducted fan coils placed inside the false ceiling.
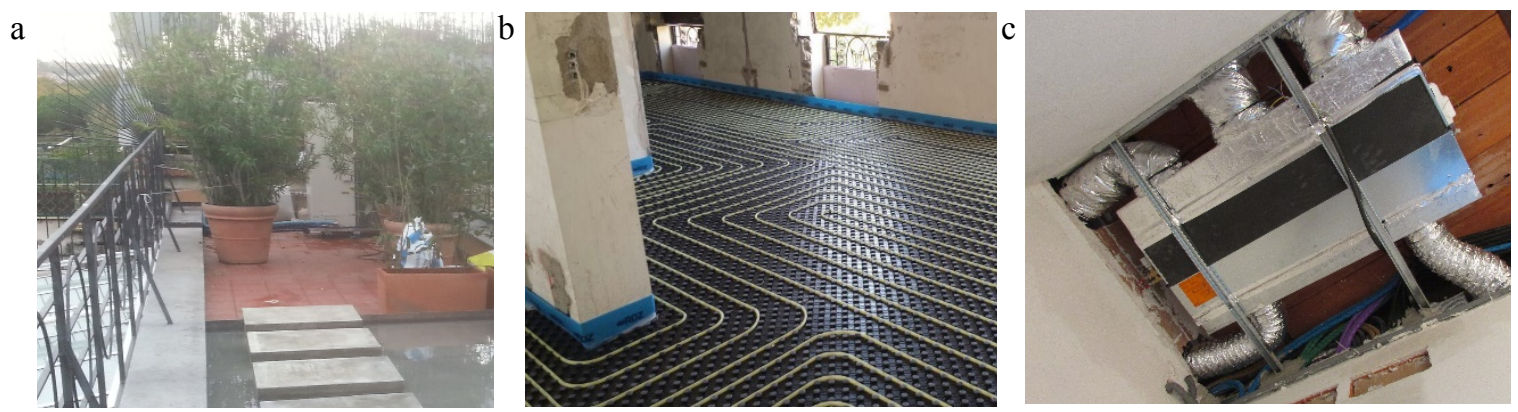

Fig. 3. Heating and cooling systems (a) Heat pump; (b) Radiant floor panels; (c) Ducted fan coils.

The regulation takes place through a centralized control system equipped with a microprocessor unit capable of autonomously controlling each terminal. The preparation of domestic hot water is carried out by the same heat pump; there is an accumulation of 80 litres. The lighting system is equipped with LED lamps with presence sensors in the living area of the house.

\subsection{Comparison between the ante operam situation and the post operam situation}

Using the performance indicators described above, Table 3 shows a comparison between the situation before and after the refurbishment.

Table 3. Comparison between the ante operam situation and the post operam situation.

\begin{tabular}{lcccc}
\hline Key Performance Indicator & Unit & Ante operam & Post operam & Range \\
\hline Winter thermal load & {$\left[\mathrm{W} / \mathrm{m}^{2}\right]$} & 77,9 & 43,1 & $-44,7 \%$ \\
Summer thermal load & {$\left[\mathrm{W} / \mathrm{m}^{2}\right]$} & 88,8 & 63,9 & $-28,0 \%$ \\
Primary energy consumption & {$\left[\mathrm{kWh} / \mathrm{m}^{2}\right]$} & 133,9 & 61,1 & $-54,4 \%$ \\
Renewable energy use & {$\left[\mathrm{kWh} / \mathrm{m}^{2}\right]$} & 5,1 & 21,2 & $+319,1 \%$
\end{tabular}




\begin{tabular}{lcccc} 
Local carbon emissions & {$\left[\mathrm{kg} / \mathrm{m}^{2}\right]$} & 20,7 & 1,3 & $-93,9 \%$ \\
Flexible loads amount & {$\left[\mathrm{kWh} / \mathrm{m}^{2}\right]$} & 6,7 & 14,1 & $+109,4 \%$ \\
\hline
\end{tabular}

For all the indicators considered, improvements after the intervention are observed. In fact, there is a decrease in winter and summer thermal loads and a decrease in primary energy consumption. Following the electrification of the heating and domestic hot water preparation utilities, local emissions are almost totally deleted $(-93.9 \%)$. For the same reason, there is a growth in the use of renewable energy $(+319.1 \%)$ and the amount of flexible loads $(+109.4 \%)$.

In absolute terms, the flexible electric loads of the house go from $1,988 \mathrm{kWh} / \mathrm{y}$ to $4,163 \mathrm{kWh} / \mathrm{y}$.

\section{Conclusions}

In this work, a refurbishment intervention has carried out in a historic building, in the Prati district in Rome. The intervention stems from the need for a renovation of the building, aimed at current use, compatible with modern standards of comfort. Being a building subject to protection constraints, the design choices have aimed at improving energy efficiency, preserving the historical aspect of the building. The values, recognized as historical, are the fundamental testimony of a recent but important phase in the history of Italian and European architecture for its formal, structural characteristics and the distribution of the artefacts.

For this reason, non-invasive interventions have been designed on the building envelope, with insulation placed on the inside of the walls and with the only replacement of the glass in the original wooden frames.

For the plants, the existing heating system has been replaced with a heating and cooling system with heat pump, fan coil units and radiant panels. This made it possible to increase overall efficiency, to increase the use of renewable energy and to significantly decrease local polluting emissions.

The result demonstrates the feasibility of energy efficiency measures and the opportunity to achieve high objectives, as the existing building stock has poor thermal performance.

\section{References}

[1] European Commission 2018 A Clean Planet for all A European strategic long-term vision for a prosperous, modern, competitive and climate neutral economy

[2] Hausladen G and Tucci F 2017 Technological culture, the environment and energy: The outlook for research and experimentation TECHNE 13 63-71

[3] Eurostat 2017 Database - Eurostat risk poverty Soc. exclusion

[4] Nastasi B 2019 Hydrogen policy, market, and R\&D projects Solar Hydrogen Production:

Processes, Systems and Technologies (Elsevier) pp 31-44

[5] Mancini F and Nastasi B 2020 Solar Energy Data Analytics: PV Deployment and Land Use Energies 13417

[6] de Santoli L, Mancini F and Astiaso Garcia D 2019 A GIS-based model to assess electric energy consumptions and usable renewable energy potential in Lazio region at municipality scale Sustain. Cities Soc. 46101413

[7] Mazzoni S, Ooi S, Nastasi B and Romagnoli A 2019 Energy storage technologies as technoeconomic parameters for master-planning and optimal dispatch in smart multi energy systems Appl. Energy 254113682

[8] Mancini and Lo Basso 2020 How Climate Change Affects the Building Energy Consumptions Due to Cooling, Heating, and Electricity Demands of Italian Residential Sector Energies 13410

[9] de Santoli L, Lo Basso G, Astiaso Garcia D, Piras G and Spiridigliozzi G 2019 Dynamic Simulation Model of Trans-Critical Carbon Dioxide Heat Pump Application for Boosting Low Temperature Distribution Networks in Dwellings Energies 12484

[10] Roversi R, Cumo F, D’Angelo A, Pennacchia E and Piras G 2017 Feasibility of municipal waste reuse for building envelopes for near zero-energy buildings WIT Trans. Ecol. Environ. 224 115-25

[11] Piras G, Pennacchia E, Barbanera F and Cinquepalmi F 2017 The use of local materials for lowenergy service buildings in touristic island: The case study of Favignana island 2017 IEEE International Conference on Environment and Electrical Engineering and 2017 IEEE Industrial and Commercial Power Systems Europe (EEEIC / I\&CPS Europe) (IEEE) pp 1-4 
[12] Mancini F, Nardecchia F, Groppi D, Ruperto F and Romeo C 2020 Indoor Environmental Quality Analysis for Optimizing Energy Consumptions Varying Air Ventilation Rates Sustainability 12 482

[13] Mancini F, Lo Basso G and de Santoli L 2019 Energy Use in Residential Buildings: Impact of Building Automation Control Systems on Energy Performance and Flexibility Energies 2019, Vol. 12, Page 2896122896

[14] De Santoli L, Mancini F and Basso G L G Lo 2019 Analysis on the potential of an energy aggregator for domestic users in the Italian electricity system AIP Conference Proceedings vol 2191 p 020062

[15] de Santoli L, Mancini F, Nastasi B and Ridolfi S 2017 Energy retrofitting of dwellings from the 40's in Borgata Trullo - Rome Energy Procedia 133 281-9

[16] Mancini F, Salvo S and Piacentini V 2016 Issues of Energy Retrofitting of a Modern Public Housing Estates: The "Giorgio Morandi” Complex at Tor Sapienza, Rome, 1975-1979 Energy Procedia vol 101 pp 1111-8

[17] Battisti A and Tucci F 2014 Technological energy and environmental refurbishment of historical Italian libraries Techne J. Technol. Archit. Environ. 0 90-108

[18] Battisti A 2016 Guidelines for energy efficiency in the cultural heritage TECHNE - J. Technol. Archit. Environ. 12 65-73

[19] Cumo F, Curreli F R, Pennacchia E, Piras G and Roversi R 2017 Enhancing the urban quality of life: A case study of a coastal city in the metropolitan area of Rome WIT Trans. Built Environ. 170 127-37

[20] Piras G, Pini F and Astiaso Garcia D 2019 Correlations of PM10 concentrations in urban areas with vehicle fleet development, rain precipitation and diesel fuel sales Atmos. Pollut. Res.

[21] Astiaso Garcia D, Cumo F, Pennacchia E, Stefanini Pennucci V, Piras G, De Notti V and Roversi R 2017 Assessment of a urban sustainability and life quality index for elderly Int. J. Sustain. Dev. Plan. 12 908-21

[22] Mancini F, Lo Basso G and De Santoli L 2019 Energy Use in Residential Buildings: Characterisation for Identifying Flexible Loads by Means of a Questionnaire Survey Energies 2019, Vol. 12, Page 2055122055

[23] Manfren M and Nastasi B 2020 Parametric Performance Analysis and Energy Model Calibration Workflow Integration-A Scalable Approach for Buildings Energies 13621

[24] Mancini F and Nastasi B 2019 Energy retrofitting effects on the energy flexibility of dwellings Energies 1217 